\title{
Rationale, design and methods of the HEALTHY study nutrition intervention component
}

\author{
B Gillis ${ }^{1}$, C Mobley ${ }^{2}$, DD Stadler ${ }^{3}$, J Hartstein ${ }^{4}$, A Virus $^{5}$, SL Volpe ${ }^{6}$, L El ghormli ${ }^{7}$, MA \\ Staten $^{8}$, J Bridgman ${ }^{9}$, S McCormick ${ }^{3}$, and for the HEALTHY Study Group \\ ${ }^{1}$ Western Psychiatric Institute and Clinic, University of Pittsburgh Medical Center, Pittsburgh, PA, \\ USA \\ ${ }^{2}$ School of Dental Medicine, University of Nevada Las Vegas, Las Vegas, NV, USA \\ ${ }^{3}$ Division of Health Promotion \& Sports Medicine, Oregon Health \& Science University, Portland, \\ OR, USA \\ ${ }^{4}$ Department of Pediatrics, University of California at Irvine, Irvine, CA, USA \\ ${ }^{5}$ Center for Obesity Research \& Education, Temple University, Philadelphia, PA, USA \\ ${ }^{6}$ Division of Biobehavioral and Health Sciences, School of Nursing, University of Pennsylvania, \\ Philadelphia, PA, USA \\ ${ }^{7}$ Biostatistics Center, George Washington University, Rockville, MD, USA \\ ${ }^{8} \mathrm{NIDDK} / \mathrm{NIH}$, Bethesda, MD, USA \\ ${ }^{9}$ School of Nursing, University of North Carolina at Chapel Hill, Chapel Hill, NC, USA
}

\section{Abstract}

The HEALTHY study was a randomized, controlled, multicenter and middle school-based, multifaceted intervention designed to reduce risk factors for the development of type 2 diabetes. The study randomized 42 middle schools to intervention or control, and followed students from the sixth to the eighth grades. Here we describe the design of the HEALTHY nutrition intervention component that was developed to modify the total school food environment, defined to include the following: federal breakfast, lunch, after school snack and supper programs; a la carte venues, including snack bars and school stores; vending machines; fundraisers; and classroom parties and celebrations. Study staff implemented the intervention using core and toolbox strategies to achieve and maintain the following five intervention goals: (1) lower the average fat content of foods, (2) increase the availability and variety of fruits and vegetables, (3) limit the portion sizes and energy content of dessert and snack foods, (4) eliminate whole and $2 \%$ milk and all added sugar beverages, with the exception of low fat or nonfat flavored milk, and limit 100\% fruit juice to breakfast in small portions and (5) increase the availability of higher fiber grain-based foods and legumes. Other nutrition intervention component elements were taste tests, cafeteria enhancements, cafeteria line messages and other messages about healthy eating, cafeteria learning laboratory (CLL) activities, twice-yearly training of food service staff, weekly meetings with food service managers, incentives for food service departments, and twice yearly local meetings and three national summits with district food

\footnotetext{
(C) 2009 Macmillan Publishers Limited All rights reserved

Correspondence: B Gillis, Western Psychiatric Institute and Clinic, University of Pittsburgh Medical Center, 3811 O'Hara Street, Pittsburgh, PA 15213, USA. gillisbp@upmc.edu.

Conflict of interest

S Volpe has received consulting fees from Gatorade Sports Science Institute. The remaining authors declare no conflict of interest.
} 
service directors. Strengths of the intervention design were the integration of nutrition with the other HEALTHY intervention components (physical education, behavior change and communications), and the collaboration and rapport between the nutrition intervention study staff members and food service personnel at both school and district levels.

\section{Keywords}

childhood obesity; diabetes prevention; food service; middle school intervention; nutrition; school food environment

\section{Introduction}

The HEALTHY study was a 3-year randomized, controlled primary prevention trial of a middle school-based intervention designed to reduce risk factors for type 2 diabetes. In all, seven centers across the country each recruited six middle schools serving largely minority and socioeconomically challenged populations. The 42 schools were subsequently randomized to control or intervention arms of the study. ${ }^{1}$ Here we describe the intervention component targeting nutrition, in which changes were made to the total school food environment. In addition, the HEALTHY intervention integrated components that modified the physical education program, ${ }^{2}$ targeted behavior change through brief classroom activities, individual and group behavior change initiatives, and family outreach, ${ }^{3}$ and promoted changes in food selection and consumption patterns, activity and behavior. ${ }^{4}$ Experts among the HEALTHY study group formed committees to design and develop each intervention component. The nutrition intervention component was the responsibility of the Nutrition Committee.

The objective of the nutrition intervention component was to improve the nutritional quality of the food and beverages available to and taken or purchased by students throughout the total school food environment, with an emphasis on changes likely to reduce the risk of overweight, obesity and type 2 diabetes. The total school food environment was defined to include the federal meal programs (the School Breakfast Program (SBP), the National School Lunch Program, (NSLP), the After-School Snack Program and the Supper Program), a la carte venues, such as snack bars and school stores, vending machines, fundraisers, and classroom parties and celebrations.

\section{Background and rationale}

According to the American Dietetic Association (ADA), ${ }^{5}$ the following foods, nutrients and eating behaviors are positively associated with childhood overweight: calorically sweetened beverages, including soft drinks; fruit juice when consumed in large quantities; skipping breakfast; consuming food away from home, particularly at fast food restaurants and especially among adolescents; increased portion sizes; and a low intake of fruits and vegetables. Frequency of family meals was positively associated with dietary quality in adolescents. Evidence of an association between each of the following factors and childhood overweight was considered limited: total energy intake, with the lack of association likely attributable to the difficulty of accurately assessing energy intake; dietary fat, although the preponderance of observational evidence suggests an association; calcium and dairy product intake; and parental control over children's dietary intake.

In light of the ADA findings, the American Academy of Pediatrics (AAP) recommended that children limit consumption of sugar-sweetened beverages and 100\% fruit juice, consume recommended quantities of fruits and vegetables, eat breakfast daily, limit eating out at restaurants and particularly fast food restaurants, eat meals frequently with their families and 
limit portions to appropriate serving sizes. ${ }^{6}$ Based on expertise in areas for which evidence is limited, the AAP also recommended that children eat a diet rich in calcium and high in fiber, and limit consumption of energy-dense foods. ${ }^{6}$

Insulin resistance and type 2 diabetes have been positively associated with overweight, specifically with excess intraabdominal fat accumulation, which is associated with energydense diets high in total fat. Insulin sensitivity may be negatively affected by saturated fat independent of its effect on body weight. ${ }^{7}$ Increased intake of insoluble fiber, particularly cereal fiber, and a diet rich in legumes, whole grains, and fruits and vegetables have been associated with a decreased risk of insulin resistance. ${ }^{8-12}$ Evidence for an effect of other nutritional factors on insulin sensitivity is limited. ${ }^{13,14}$

Previous interventions to improve the dietary intake of middle-school students have reported limited success. One 2-year intervention to increase student intake of lower-fat foods from the cafeteria, a la carte venues and home lunches ${ }^{15}$ and another of similar duration with environmental changes, peer leaders and parent activities, ${ }^{16}$ reported little or no change in student dietary intake. Reviews of school-based obesity prevention programs, including nutrition components, have reported insufficient evidence to provide definitive guidance to programs due to methodological and other concerns. ${ }^{17,18}$

Environmental influences on student eating behaviors are complex and extensive. ${ }^{19,20}$ Numerous regulations from the United States Department of Agriculture (USDA) govern the Federal School Meals Programs, including the minimal nutritional content of meals, the type and number of food items and serving sizes, depending on the menu planning approach used by the school. Competitive foods, which are those sold outside of the Federal School Meals Programs and include a la carte, snack bar and vending items, are largely unregulated. ${ }^{21}$ They often generate substantial revenues for food-service operations and/or school activities, and at many schools include popular, energy-dense items such as candy, soft drinks, other added sugar beverages and high-fat snacks, such as regular chips and cookies. The consumption of competitive low-nutrient, energy-dense foods is widespread, especially in secondary schools. ${ }^{20}$ One study showed that the availability of competitive foods in school cafeterias has increased the intake of fat and sugars, reduced the intake of certain vitamins and calcium and modestly increased the total energy supplied by meals. ${ }^{22}$ Reducing portion sizes of snack bar items to smaller, single serving packages in another study saved $47 \mathrm{kcal}$ per student per day, a small deficit that over time could contribute to the prevention of weight gain. ${ }^{23}$ The obesity epidemic in the United States has been accompanied by an increase in food product portion sizes since the 1970s. ${ }^{24}$

To improve children's diets and reduce obesity, the School Nutrition Dietary Assessment Study-III has recommended that schools need to do more to limit the availability of highcalorie, low-nutrient foods and make school meals more nutritious. This includes serving only nonfat or $1 \%$ low-fat milk, reducing the frequency of offering fried potatoes and higher-fat baked goods, removing sugar-sweetened beverages, limiting access to low nutrient, energy dense competitive foods, and offering more fruits, vegetables and whole grains. ${ }^{25}$

\section{Nutrition pilot studies}

Three pilot studies that were conducted in preparation for the HEALTHY study included a nutrition component. ${ }^{1,26,27}$ The nutrition intervention component goals tested were to increase water, decrease serving sizes of sweetened beverages, increase fruits and vegetables, reduce the fat content of meals and snacks, restrict the portion size of snack foods, promote healthful food offerings, increase whole grains, limit whole and $2 \%$ milk and limit fruit juice to small amounts at breakfast only. The overall goal achievement was high. Recommendations for the full-scale trial were to expand the goals to eliminate added sugar beverages and increase 
legumes, conduct educational activities in the cafeteria to inform students about the purpose of the changes that were implemented, more actively market healthy items, develop targeted strategies to alter vending options, and continue to assess financial data and data on the nutrients in foods available and served. An educational activity in the cafeteria and school-wide posters promoting water were tested and found to be popular with students and feasible as vehicles for intervention delivery.

\section{Features of the nutrition intervention component}

The nutrition intervention component was conducted by nutrition professionals (one full-time equivalent per center) referred to for this study as research dietitians. Most, but not all, were registered dietitians. The research dietitians attended annual study trainings and biannual study group meetings, were encouraged to attend National School Nutrition Association conferences and held weekly conference calls.

The major role of the research dietitian was to implement the elements of the nutrition intervention component described below. In the control schools, the research dietitian's role was restricted to pre-intervention activities that included the following: (1) contributing to school recruitment, (2) collecting product information to customize the nutrient database for analyses of items available to students during data collection periods and (3) training food service managers on baseline nutrition data collection.

The nutrition intervention component provided design features that could be implemented in both standardized and flexible ways. Each school assigned to receive the intervention was expected to achieve and maintain the intervention goals. However, flexibility was needed because school districts, individual schools and food service departments not only varied greatly in size, management structure, and resources, but also they were continually changing. The research dietitians were required to work with a wide variety of stakeholders with financial and other interests, including food service and school administrators, faculty, students, and food and beverage vendors. For example, menu planning required flexibility because various menu planning approaches were used in different schools, including the traditional food-based menu planning approach, the nutrient standard approach and alternate approaches. ${ }^{28}$ The research dietitians at some centers also worked with as many as three different school districts, each with its own operations. The research dietitians were required to adapt to the demands and styles of the schools and districts without compromising the intervention goals.

Another feature of the intervention design was the integration across nutrition, physical education and behavior components through school-wide communications strategies. For example, the research dietitians participated in student assemblies and events at the schools and provided nutrition messaging for all areas of the multi-component intervention, as described below.

A third feature of the intervention was that it reflected an ecological model of the myriad influences on student dietary intake. ${ }^{29,30}$ These included individual food choices, peer/family influences, food provided by the school and district, and other sources of food in the school, such as vending machines, fundraisers and celebrations.

\section{Goals, core strategies and toolbox strategies}

Central to the nutrition intervention component were five goals, listed in Table 1 with a summary of the evidence for each. The goals used the term 'serve' to describe what foods and beverages the intervention aimed to have students purchase or take from the total school food environment ('take' referred to items provided in free meals). 
For each goal, multiple strategies were developed. The strategies used the term 'offer' to describe what foods and beverages were to be made available to the students in the total school food environment. By changing the items available to students, the strategies were meant to accomplish the goals, that is, to change what the students purchased or took from the environment. The strategies that were highly likely to have a significant effect on the ability of schools to achieve the intervention goals were named 'core strategies' (see Table 2). All centers were expected to implement core strategies as soon as possible after baseline data were collected and to maintain them throughout the intervention. Strategies designed to keep the intervention fresh, to tailor it to differences among schools, and to go above and beyond the core strategies, were named 'toolbox strategies' (see Table 3). Some of the toolbox strategies were not applicable to all schools because of cafeteria design or other reasons.

A goal to specifically lower the energy content of foods other than snacks and desserts was not set, given that United States Department of Agriculture regulations mandate the minimum energy content of the meals offered in federal school meals programs. However, the effect on the energy content of foods was considered as the goals and strategies were implemented. For example, a research dietitian was expected to consider the difference in the energy of food options when deciding which higher fiber bread products or lower fat entrees to recommend, with an overall intent to avoid increasing the energy content of meals and snacks.

For the goals and strategies, an 'added sugar beverage' was defined as any beverage with nutritive sweeteners added, such as soft drinks, fruit punch, fruit juice with less than $100 \%$ juice and sweetened iced tea. Flavored milks were considered an exception because of the nutritional value of milk. However, because of the high energy content of large servings of flavored milk, one of the toolbox strategies limited the portion size of flavored $1 \%$ fat or nonfat milk to 12 ounces or less.

Owing to the long lead time needed for school food service planning, as soon as schools were randomized, study research dietitians began working with intervention school food service staff to review food bids and order new or additional items. Where both intervention and control schools were organized under a single food service operation, special exceptions had to be made to accommodate the study goals in the intervention schools. This had local financial implications that were addressed with study compensation described below.

The strategies meant to influence the school community outside of food service were recognized as a particular challenge. Fundraisers, classroom parties, and celebrations under the direct purview of teachers and school administrators made consistently maintaining the strategies challenging. With regard to vending, three core strategies- to eliminate all added sugar beverages, limit snacks to less than $200 \mathrm{kcal}$ in single-serving packages, and offer only reduced-fat or baked chips-were considered uniquely challenging because of the schools' financial interests in vending programs, and contracts with beverage and snack vending companies. Distributors of vending items were often difficult to reach, and schedules for restocking the machines were typically irregular. Information about alternative items was not always readily provided, and follow-through after plans for change were agreed upon was often inconsistent.

To achieve the goals and strategies, the research dietitians used behavioral techniques to encourage the food service directors and managers to change the foods available to the students. During weekly meetings with the managers at each school, the research dietitians reviewed any progress made toward implementing the strategies. Step-wise goals to move forward were developed and anticipated barriers were discussed in detail. Possible solutions for each barrier were reviewed and evaluated, and one or two solutions were selected by the food service managers to try. If needed, the food service director and buyer were consulted regarding menu 
changes or the purchase of new products. Food distributors were contacted and specifications for products that might better meet the intervention goals were requested and reviewed. Outside vendors and teachers or school administrators were consulted regarding changes required in items sold through vending, fundraisers or school stores.

\section{Educational and promotional activities}

In collaboration with the communications intervention component, two types of activities were held in the schools for the purpose of educating and promoting good nutrition choices and behaviors. ${ }^{4}$ One was called a taste test and the other a cafeteria learning laboratory (CLL). Both activities were designed to be fun and broadly participatory. Implementation of the activities involved not only study staff members, but students as well to take advantage of peer dynamics.

The research dietitians conducted 1-3 taste test events per school per semester. Taste tests were intended to promote student selection of products that supported study goals and to provide districts with documentation of the student response to new items, thereby supporting the financial risk that districts take when bringing in new items. The items tested were either provided without cost by food manufacturers, as is typical when districts sample new products, or by the study. Items were selected that would introduce students to products and tastes that they had not experienced before or that were newly available, such as whole grain turkey corn dogs, veggie burgers, zucchini coins, kiwi fruit and black bean empanadas. Students indicated by voting how well they liked the items tested, and results were tallied and posted.

In each semester in each school, the research dietitians also conducted an activity in the cafeteria to educate students about the intervention's rationale, and motivate them to make healthy food and beverage choices both in and out of school. The activity was called the cafeteria learning laboratory. Visuals and props were used to enhance the experience. For example, in an activity called 'Snacktive: Snack Smart and Be Active,' students guessed from multiple choices how much physical activity was needed to burn off the energy in four different snacks (an apple, a popsicle, a bag of baked potato chips and a large cookie). As part of the activity, the study staff encouraged the students to choose lower energy snacks in small portions. For three of the cafeteria learning laboratories, students answered questions related to the activity on game cards and the cards were entered into a raffle for small prizes.

\section{Cafeteria enhancements}

Given that attractive food presentation enhances its acceptance, the study provided $\$ 125$ per school per semester for cafeteria enhancements, such as attractive serving dishes, trays and signage. In addition, food service managers and staff were given study-branded aprons, tops and hats. In several schools, painting a mural in the cafeteria conveying healthy lifestyle activities became a project that involved art classes.

\section{Messaging}

Experts on the Nutrition Committee developed brief messages about healthy eating that were displayed on or near the cafeteria serving lines. The messages were based on the study-wide themes for each semester, with most relating to the nutrition intervention goals, although physical education and behavioral topics were included. Sometimes the messages were paired in Q\&A format. Later in the study, the messages consisted of photographs of the students and quotations from them, which were collected as part of the communications intervention component student-generated media campaigns. ${ }^{4}$

Other message placement resulted from the integration of components within the HEALTHY intervention. Extensive nutrition content was developed for the behavior intervention 
component Fun Learning Activities for Student Health (FLASH) curriculum that was delivered in the classroom by teachers and facilitated by peers during 10 weekly sessions each semester. ${ }^{3}$ Healthy eating messages were also featured on study-wide posters, read over the school public address system, and read by physical education teachers while students cooled down after physical education classes. ${ }^{2,4}$ The study sent home newsletters to parents during the 3-year intervention that included parent testimonials related to healthy eating, ethnically diverse recipes and healthy eating tips, such as the importance of eating breakfast and eating meals as a family. During the summer between seventh and eighth grades and during the eighth-grade winter break, students were sent home with a kit challenging them to maintain healthy eating and physical activity. ${ }^{3}$ The kits included nutrition related items, such as a heart healthy cookbook, a booklet with nutrition content and a study-branded cutting board. The research dietitians also disseminated healthy eating messages to teachers and school administrators. Teachers and administrators were encouraged to substitute nonfood items for rewards, fundraisers, and classroom celebrations and parties.

\section{Training and meetings}

The research dietitians conducted an initial training followed by one booster training per semester for the intervention school food service managers and staff. Introductory training described the risk factors for type 2 diabetes in middle-school age adolescents, explained the HEALTHY trial and presented the nutrition intervention component in detail. Booster training sessions focused on the status of goals and strategies in the schools, and what nutrition activities were planned for the upcoming semester. On a weekly basis, the research dietitian met with each intervention school food service manager to plan ways to reach, maintain, and go beyond the targeted goals and strategies, problem solve barriers, reinforce successes and observe the foods and beverages in the total school food environment. Food and beverage specifications, sales and meal production records and menus were reviewed to ascertain ways to meet the intervention goals.

Meetings were also planned at the school district level. During recruitment in each potential school district, the research dietitian met with the food service directors and other district food service staff, described the intervention, and answered questions. After school randomization, the research dietitian met at least once per semester with the directors and other district level staff, such as buyers, to develop rapport, maintain study buy-in, and procure foods and beverages to meet the intervention goals. The research dietitian shared with district staff what was learned at the food service manager meetings and from observations of the total school food environment. This informed the development of menus and recipes unique to the intervention schools that supported the intervention goals. The research dietitian emphasized with food service administrators the critical importance of not making changes called for by the intervention at any control schools in the district. In addition, three national summits for the food service directors from all of the intervention schools were held to foster study-wide collaboration and buy-in.

Rapport with food service directors was critical to implementing the intervention, given that they oversee the actions of the buyers and food service managers and influence outside food vendors. The directors also influenced the total school food environment through district-wide school wellness policies, mandated by the Child Nutrition and Women Infants and Children (WIC) Reauthorization Act of 2004, to be established by the start of the 2006-2007 school year. If wellness policies or other state or local policies resulted in food service changes that equaled or exceeded the nutrition goals or strategies, the research dietitians were expected to implement toolbox strategies so the changes at the intervention schools exceeded district-wide changes. 


\section{Compensation and incentives}

Food service directors received $\$ 3000$ per intervention school per year for the food service department budget to help offset costs associated with the intervention and to encourage an ongoing commitment to the study. Food service staff at the intervention schools received \$25 in personal gift cards for attending trainings and periodically received small incentives to support buy-in, such as study-branded shirts, mugs and mouse pads. Starting in year two, managers received $\$ 100$ per half-year for participating in data collection and helping to document delivery of the intervention.

\section{Discussion and summary}

A unique strength of the HEALTHY intervention was the intentional and pervasive integration of the four components of nutrition, physical education, behavior and schoolwide communications. Synergistic inter-relationships meant that the whole was greater than the sum of the parts. Within the nutrition intervention component, the establishment of intensive, persistent collaboration between the research dietitians and food service personnel at both district and school levels proved essential to the implementation of the goals and strategies. Three national summits emphasized the critical role played by district food service directors, and allowed the directors to witness the commitment of their professional peers to the intervention goals and strategies. Support at the highest levels in turn empowered the food service managers and staff at each school. In addition, targets for change were clearly defined. The use of behavioral techniques with the food service managers enhanced implementation of changes.

Limitations of the nutrition intervention component were often economic in nature.

Documentation of vending sales was hard to capture or unavailable at many schools because of limited interest from vending distributors and the lack of technologically advanced machines to track sales. Many higher fiber products were too costly for the school districts because food manufacturers were only beginning to respond to increasing secular demand for such products. At some schools, influencing fundraising and food in the classrooms was limited because of the financial interests of school administration and/or teachers. The economic downturn at local, state, and federal levels during the trial included escalated food and energy costs, which challenged food service department budgets. National events related to food safety made several key food items unavailable for periods of time. Owing to staff and budget constraints, the study was unable to collect 24-h dietary recalls from students or provide extensive nutrition outreach to students and parents.

For future school-based nutrition interventions, one recommendation is to initiate national summits for food service directors from the start of the intervention, rather than midstream as was the case in the present study. Also, study staff should receive comprehensive hands-on training on the technical aspects of the school food service before the start of the intervention, rather than during the initial stages as was the case with HEALTHY. More extensive nutrition outreach beyond school with students and families, as well as inclusion of the surrounding neighborhood food environment as part of the total school food environment, would broaden the scope of the intervention.

In summary, the HEALTHY nutrition intervention component focused on the total school food environment, was thoroughly integrated with other study components, and maintained strong relationships with food service administrators and staff. Given its many strengths, the features and components of the intervention may provide a framework for future school-based studies. The intervention may also inform policies related to the role of the total school food environment in the prevention of childhood obesity and type 2 diabetes. 


\section{Acknowledgements}

Investigators on the Nutrition Committee were Connie Mobley (chair), Karen Cullen, Laure El ghormli, Bonnie Gillis, Jill Hartstein, Mingyan Huang, Phyllis Kennel, Sara Mazzuto, Anna Maria Siega-Riz, Diane Stadler, Myrlene Staten, Stella Volpe and Mamie White. Research dietitians were Jessica Bridgman, Joette Garza, Charlene Holabird, Sarah McCormick, Becky Meehan, Mandie Oceguera and Amy Virus. We certify that all applicable institutional and governmental regulations concerning the ethical use of human volunteers were followed during this research.

\section{References}

1. The HEALTHY Study Group. HEALTHY study rationale, design and methods: moderating risk of type 2 diabetes in multi-ethnic middle school students. Int J Obes 2009;33(Suppl 4):S4-S20.

2. McMurray RG, Bassin S, Jago R, Bruecker S, Moe EL, Murray T, et al. for the HEALTHY Study Group. Rationale, design and methods of the HEALTHY study physical education intervention component. Int J Obes 2009;33(Suppl 4):S37-S43.

3. Venditti EM, Elliot DL, Faith MS, Firrell LS, Giles CM, Goldberg L, et al. for the HEALTHY Study Group. Rationale, design and methods of the HEALTHY study behavior intervention component. Int J Obes 2009;33(Suppl 4):S44-S51.

4. DeBar LL, Schneider M, Ford EG, Hernandez AE, Showell B, Drews KL, et al. for the HEALTHY Study Group. Social marketing-based communications to integrate and support the HEALTHY study intervention. Int J Obes 2009;33(Suppl 4):S52-S59.

5. American Dietetic Association. Childhood Overweight Evidence Analysis Project. 2006 [accessed 20 February 2009]. updatedAvailable at www.adaevidencelibrary.com/topic.cfm?cat=1046

6. Davis MM, Gance-Cleveland B, Hassink S, Johnson R, Paradis G, Resnicow K. Recommendations for prevention of childhood obesity. Pediatrics 2007;120:S229-S253. [PubMed: 18055653]

7. Riccardi G, Giacco R, Rivellese AA. Dietary fat, insulin sensitivity and the metabolic syndrome. Clin Nutr 2004;23:447-456. [PubMed: 15297079]

8. Esmaillzadeh A, Kimiagar M, Mehrabi Y, Azadbakht L, Hu FB, Willett WC. Dietary patterns, insulin resistance, and prevalence of the metabolic syndrome in women. Am J Clin Nutr 2007;85:910-918. [PubMed: 17344515]

9. Venn BJ, Mann JI. Cereal grains, legumes and diabetes. Eur J Clin Nutr 2004;58:1443-1461. [PubMed: 15162131]

10. Weickert MO, Pfeiffer AF. Metabolic effects of dietary fiber consumption and prevention of diabetes. J Nutr 2008;138:439-442. [PubMed: 18287346]

11. Krishnan S, Rosenberg L, Singer M, Hu FB, Djoussé L, Cupples LA, et al. Glycemic index, glycemic load, and cereal fiber intake and risk of type 2 diabetes in US black women. Arch Intern Med 2007;167:2304-2309. [PubMed: 18039988]

12. Villegas R, Gao Y-T, Yang G, Li H-L, Elasy TA, Zheng W, et al. Legume and soy food intake and the incidence of type 2 diabetes in the Shanghai Women's Health Study. Am J Clin Nutr 2008;87:162167. [PubMed: 18175751]

13. Sheard NF, Clark NG, Brand-Miller JC, Franz MJ, Pi-Sunyer FX, Mayer-Davis E, et al. Dietary carbohydrate (amount and type) in the prevention and management of diabetes: a statement by the American Diabetes Association. Diab Care 2004;27:2266-2271.

14. American Diabetes Association. Nutrition recommendations and interventions for diabetes: a position statement of the American Diabetes Association. Diab Care 2008;31:S61-S78.

15. Sallis JF, McKenzie TL, Conway TL, Elder JP, Prochaska JJ, Brown M, et al. Environmental interventions for eating and physical activity: a randomized controlled trial in middle schools. Am J Prev Med 2003;24:209-217. [PubMed: 12657338]

16. Lytle LA, Murray DM, Perry CL, Story M, Birnbaum AS, Kubik MY, et al. School-based approaches to affect adolescents' diets: results from the TEENS Study. Health Educ Behav 2004;31:270-287. [PubMed: 15090126]

17. Kropski JA, Keckley PH, Jensen GL. School-based obesity prevention programs: an evidence-based review. Obesity 2008;16:1009-1018. [PubMed: 18356849]

18. Katz DL, O’Connell M, Njike VY, Yeh M-C, Nawaz H. Strategies for the prevention and control of obesity in the school setting: systematic review and meta-analysis. Int J Obes 2008;32:1780-1789. 
19. American Dietetic Association. Position of the American Dietetic Association: local support for nutrition integrity in schools. J Am Diet Assoc 2006;106:122-133. [PubMed: 16390677]

20. Briefel RR, Crepinsek MK, Cabili C, Wilson A, Gleason PM. School food environments and practices affect dietary behaviors of US public school children. J Am Diet Assoc 2009;109:S91-S107. [PubMed: 19166677]

21. GAO Report to Congressional Requesters. School meal programs: competitive foods are widely available and generate substantial revenues for schools. 2005 [accessed 20 February 2009]. Available at 222.gao.gov/cgi-bin/getrpt? GAO-05-563

22. Templeton SB, Marlette MA, Panemangalore M. Competitive foods increase the intake of energy and decrease the intake of certain nutrients by adolescents consuming school lunch. J Am Diet Assoc 2005;105:215-220. [PubMed: 15668677]

23. Cullen KW, Thompson DI. Texas school food policy changes related to middle school a la cartel snack bar foods: potential savings in kilocalories. J Am Diet Assoc 2005;105:1952-1954. [PubMed: 16321604]

24. Young LR, Nestle M. The contribution of expanding portion sizes to the US obesity epidemic. Am J Public Health 2002;92:246-249. [PubMed: 11818300]

25. Story M. The Third School Nutrition Dietary Assessment Study: findings and policy implications for improving the health of US children. J Am Diet Assoc 2009;109:S7-S13. [PubMed: 19166675]

26. Cullen KW, Hartstein J, Reynolds KD, Vu M, Resnicow K, Greene N, et al. Improving the school food environment: results from a pilot study in middle schools. J Am Diet Assoc 2007;107:484-489. [PubMed: 17324667]

27. Hartstein J, Cullen KW, Reynolds KD, Harrell J, Resnicow K, Kennel P. Impact of portion-size control for school a la carte items: changes in kilocalories and macronutrients purchased by middle school students. J Am Diet Assoc 2008;108:140-144. [PubMed: 18156001]

28. United States Department of Agriculture Food and Nutrition Service. Menu Planner for Healthy School Meals. 2008 [accessed 16 February 2009]. revisedAvailable at http://teamnutrition.usda.gov/Resources/menuplanner.html

29. Davison K, Birch LL. Childhood overweight: a contextual model and recommendations for future research. Obes Rev 2001;2:159-171. [PubMed: 12120101]

30. Glanz K, Sallis JF, Saelens BE, Frank LD. Healthy nutrition environments: concepts and measures. Am J of Health Promot 2005;19:330-333. [PubMed: 15895534] 


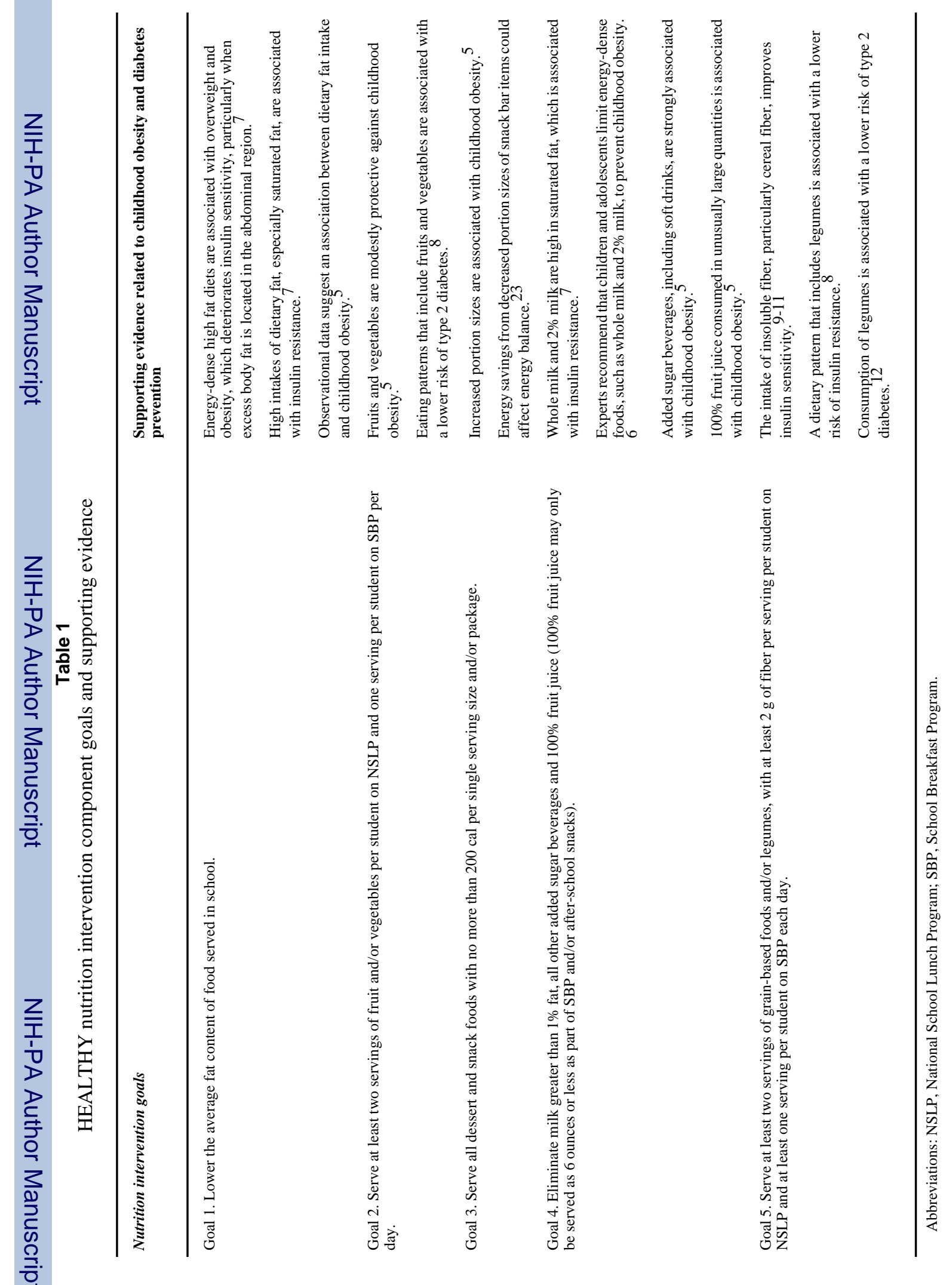




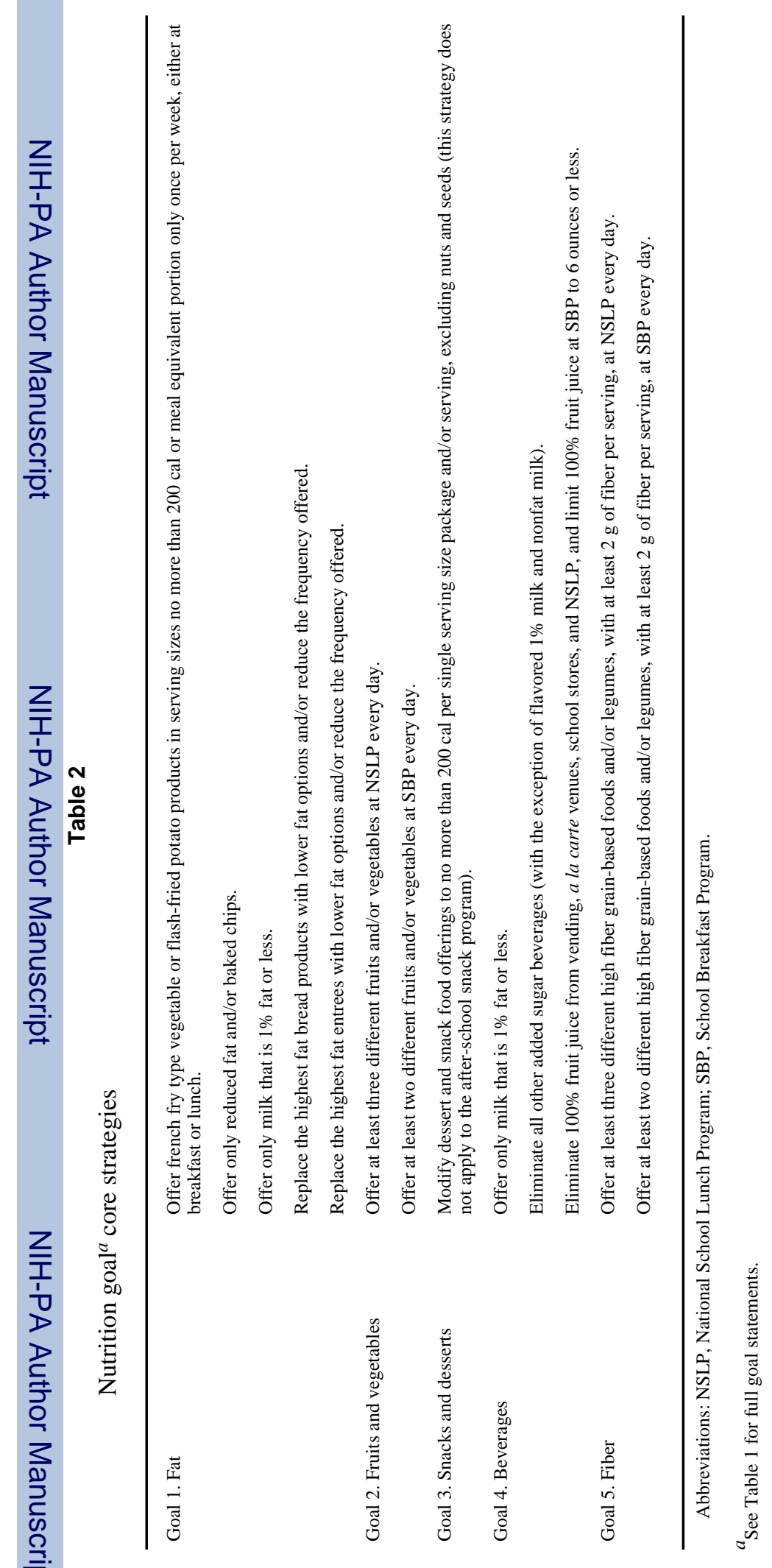

Int J Obes (Lond). Author manuscript; available in PMC 2009 September 30. 


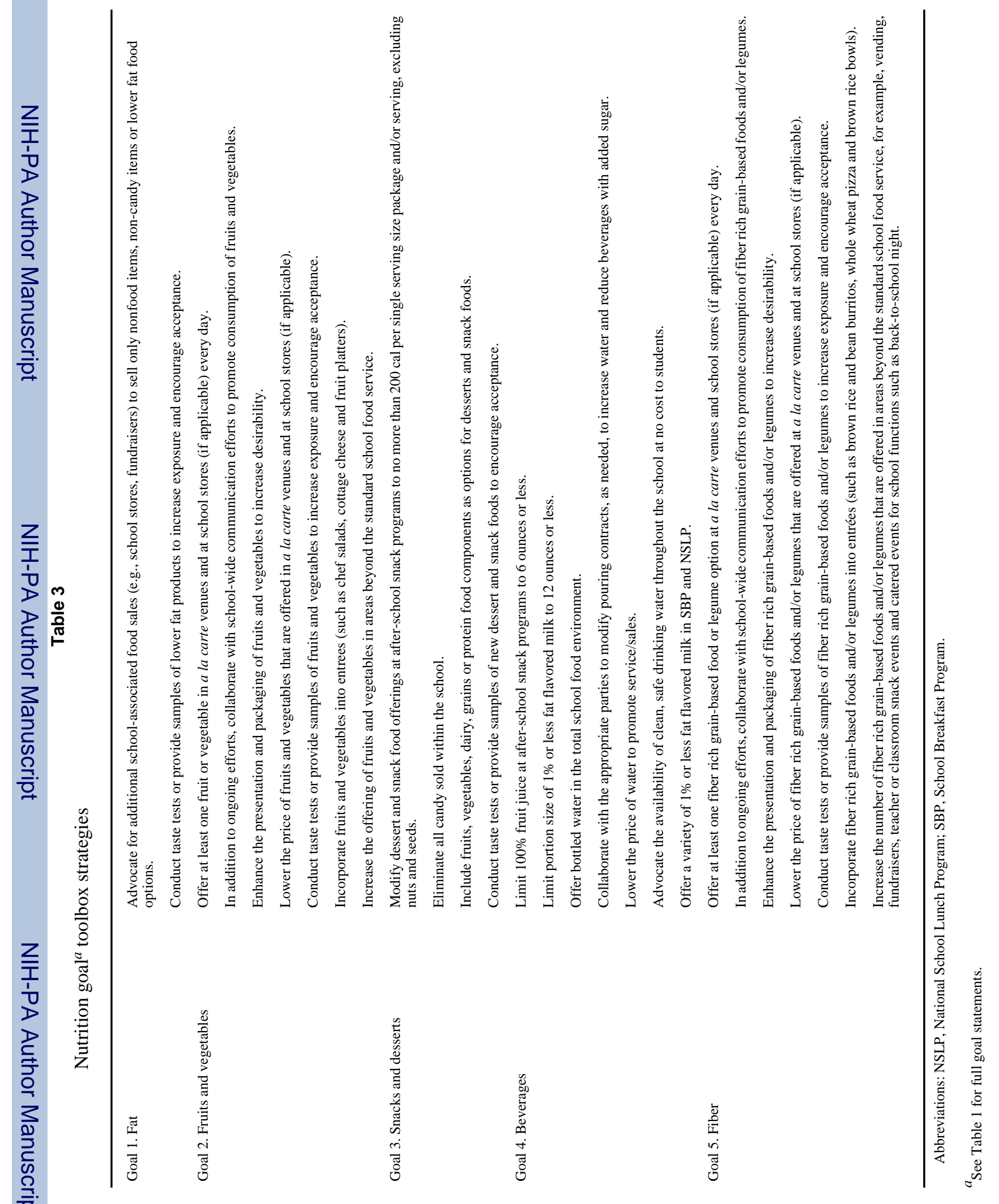

